\title{
Frost resistance of cement-sand and concrete beams during unilateral freezing
}

\author{
Nepomyach Alexander Nikolaevich \\ Odessa State Academy of Civil Engineering and Architecture \\ Vyrovoy Valeriy Nikolaevich \\ Odessa State Academy of Civil Engineering and Architecture \\ Chistyakov Artem Aleksaedrovich \\ Odessa State Academy of Civil Engineering and Architecture
}

\begin{abstract}
.
The work investigates changes in the beam structure under the action of local freezing, which leads to a change of the mechanical properties of the material and, consequently, of the beam structure. Two types of beam samples were used: from cement-sand mortar and from concrete. The work investigates the change in the development of deformations depending on the conditions of freezing of samples. The second accelerated method for assessing frost resistance was chosen according to DSTU B B.2.7-47-96. An accelerated method was chosen for assessing frost resistance at the temperature of $-20 \pm 2 \mathrm{C}^{\circ}$. After every five freeze-thaw cycles, the following changes were monitored: mass, water absorption, ultrasound transmission rate, damage coefficient, tensile bending strength, splitting strength, compressive strength, carbonization depth. The results showed that both in concrete and in mortar samples, the compressive strength after freezing was lower by $8 \%$ and $15 \%$ accordingly. The experimental results obtained confirm the assumptions made that the frost resistance of the material depends on the conditions of exposure of negative temperatures on products and structures and it can be used in a wider range of construction which will push regional development.
\end{abstract}

Keywords: cement-sand mortar, concrete, beam, deformations, localized freezing and thawing, material properties, structural changes.

Paper type: Research article

Received: 25.1.2021.

Accepted: 22.2.2021.

DOI: $10.2478 /$ crdj-2021-0009 


\section{Introduction}

Existing methods for assessing frost resistance of building materials are based on the assumption that the samples, after moistening, are subjected to a comprehensive effect of negative temperatures (Powers, 1945, Sheikin et al., 1927 Podvalny, 2004). Analysis of the operating conditions of most building products and structures (enclosing structures of buildings and structures of various values, dams, canal lining, pressure and non-pressure pipes, power lines, etc.) showed that, as a rule, external climatic loads act on them unilaterally or locally. It can be assumed that under these types of influences, the behavior of materials of products will differ significantly from their behavior during freezing. For a more objective assessment of frost resistance, the task of analyzing the conditions of external influence of negative temperatures on the change in the physicochemical characteristics of solutions and concretes is actual.

Many contemporary authors have dealt with the problem of frost resistance of materials (Sheikin et al., 1927, Podvalny, 2004, Kuntsevich, 1981, Dobshits, 2007, Rusin, 2002, Powers, 1945).

Existing methods for assessing the frost resistance of building materials are based on the assumption that the samples after wetting are exposed by the negative effects of negative temperatures. These theories formed the basis of the main hypotheses that explain the occurrence of stresses that occur in building materials, as capillary porous bodies, as a result of ice formation (Rusin, 2002, Dobshits, 2007).

The analysis of the main hypotheses for decreasing of frost resistance showed that there is practically no scientific and technical information on the effect of freezing conditions of products (samples) on the ability of the material to perceive the development of deformation with an increase in the volume of freezing water without destruction.

The purpose of the work is to assess the conditions of fully and one-sided freezing of samples to change the physicochemical characteristics and frost resistance of building materials.

\section{Methodology}

Samples - beams $(40 \times 40 \times 160 \mathrm{~mm}$.) were taken as objects of study and analysis made of cement-sand mortar (cement/send $=1 / 2$ and $\mathrm{W} / \mathrm{C}=0,5$ ). For concrete samples were formed prism samples with dimensions $100 \times 100 \times 400 \mathrm{~mm}$. Concrete design grade C30/40 at W/C $-0,48$.

Each type of sample was divided into three groups:

The first group (O1) includes samples that were tested in accordance with existing regulatory requirements (DSTU B V. 2.7-47-96).

The second group (O2) includes samples that were tested under conditions of one-sided freeze-thaw. Part of the sample passed freeze-thaw (O2-), and the other part was in the zone of the positive temperature range $(\mathrm{O} 2+)$.

The third group (O3) includes samples that were in the normal hardening chamber. 
There are two typical ways of freezing samples. The first method is to freeze the premoistened entire sample. This method has been used for more than a hundred years as a basic normative method for quantifying the frost resistance of building materials of various types and purposes (DSTU B V.2.7-47-96). The second method is associated with one-sided exposure of negative temperatures. Changing of the freezing conditions noticeably changes the formation of the freezing front, which leads to a change in the internal heat and mass transfer, pinching or displacement of the gas component, the emergence and development of moisture and temperature deformations, etc (Nepomyashchy et. al. 2020). This suggests that a change in the freezing conditions of samples will make it possible to more objectively assess the frost resistance of materials and develop adequate recipe and technological methods for increasing their resistance, depending on the type and operating conditions of the product and structures.

The second method for assessing frost resistance was chosen. After every five freeze-thaw cycles, it was monitored following characteistics: mass $(\Delta \mathrm{m})$, water absorption $(w)$, ultrasound speed through sample $(\mathrm{U})$, damage coefficient $\left(\mathrm{K}_{\Pi}\right)$, bending tensile strength (fctk), splitting strength (fctn), compressive strength (fck), carbonation depth $(\lambda)$. Table 1.

Table 1

Tests of the influence of different types of freezing and thawing

\begin{tabular}{cllll}
\hline \multirow{2}{*}{ Trials } & \multicolumn{3}{l}{ Material } & Concrete \\
\cline { 2 - 5 } & Mortar & & $\mathbf{0 1}$ & $\mathbf{0 2}$ \\
\cline { 2 - 5 } & $\mathbf{0 1}$ & $\mathbf{0 2}$ & 24 & 24 \\
\hline $\mathbf{\Delta} \mathbf{w}$ & 24 & 24 & 24 & 24 \\
\hline $\mathbf{u}$ & 24 & 24 & 28 & 96 \\
\hline $\mathbf{D F}$ & 48 & 96 & 24 & 24 \\
\hline $\mathbf{f}_{\mathrm{ctk}}$ & 24 & 24 & 24 & 24 \\
\hline $\mathbf{f}_{\mathrm{ctn}}$ & 24 & 24 & 48 & 48 \\
\hline $\mathbf{f}_{\mathbf{c k}}$ & 48 & 48 & 48 & 48 \\
\hline
\end{tabular}

The mass of the samples was determined using scales with a division of $0.1 \mathrm{~g}$

Determination of water absorption of samples was carried out in accordance with DSTU $B$ V.2.7-47-96: 2008 " using an oven that maintains a temperature of $95 \pm 5^{\circ} \mathrm{C}$.

The speed of ultrasound was determined using the device $\mathrm{УK}-14 \sqcap \mathrm{M}$, in a completely dried condition in accordance with DSTU B V.2.7-220:2009.

Devices ІПС-МГ4.03 are designed for operational non-destructive testing of strength and homogeneity of concrete and mortar by the method of shock pulse according to DSTU B 
V.2.7-220:2009. The strength of the samples is determined according to DSTU B V.2.7214:2009.

All results samples strength were obtained on a standard hydraulic press. The strength of concrete, $\mathrm{MPa}\left(\mathrm{kgf} / \mathrm{cm}^{2}\right)$, is calculated with an accuracy of $0.1 \mathrm{MPa}\left(1 \mathrm{kgf} / \mathrm{cm}^{2}\right)$ in compression tests and up to $0.01 \mathrm{MPa}\left(0.1 \mathrm{kgf} / \mathrm{cm}^{2}\right)$ in tensile tests for each sample. Figure 1 .

\section{Figure 1}

Compressive and bending strength equipment.

a) standard hydraulic press, b) bending test equipment

a)

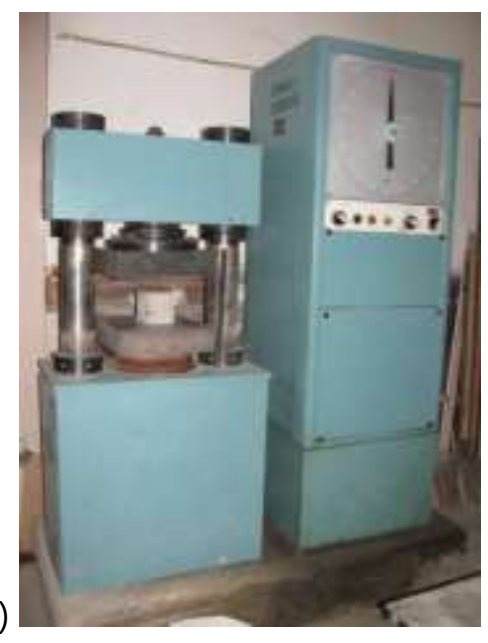

b)

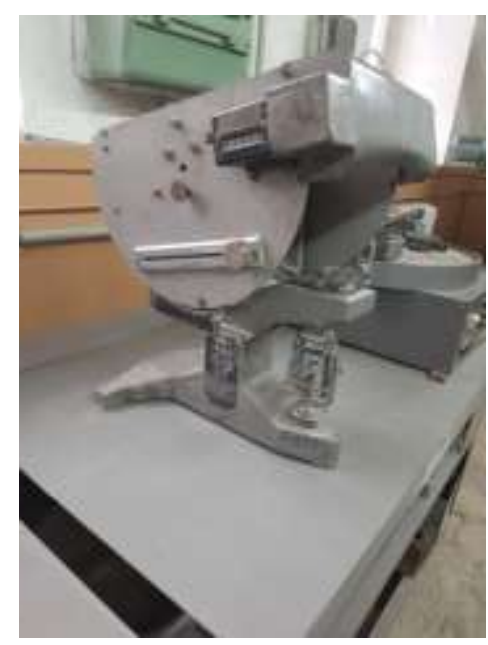

Source: Author's illustration

As a basic method for detecting technological cracks in cement stone and concrete, the method described in the Patent of Ukraine № 5735 was adopted. The essence of the method is that the sample or fragment of the sample is placed for a fixed time in an aqueous solution of tannin at a given concentration at a temperature of $100{ }^{\circ} \mathrm{C}$. The pattern of cracks is "printed" on the open surfaces of the samples, which allows to measure their total length and find the ratio of the crack length to the surface area on which they appeared.

The method of calculating the damage factor (DF) was used for quantitative assessment. To determine the damage factor (DF), the total length of the defects was correlated with the surface area on which they appeared. The total length $L$ is defined as the sum of the lengths of the active elements.

$$
\begin{aligned}
& L=I_{1}+I_{2}+\ldots+I_{i} \\
& D F=L / a^{2} \mathrm{~cm} / \mathrm{CM}^{2}
\end{aligned}
$$

where $L-$ is the total length of cracks, see, $\left.\right|_{1}, I_{2} \ldots . l_{i}-$ is the length of the crack fragment, $\mathrm{cm}$; $\mathrm{a}-$ is the area on which the cracks are, $\mathrm{cm}^{2}$. 


\section{Results}

The experimental results showed, for samples from solution, that with an increasing in the number of cycles, water absorption decreases with one-sided freezing to $18 \%$ with all-round freezing up to $25 \%$.

A change of water absorption during multiple freezing cycles indicates a change of the pore structure, which is indirectly confirmed by an increase of the ultrasound speed with an increase in the number of cycles. Structural transformations are confirmed by the test results of the effect of freezing conditions on the change in the carbonization depth - with allround freezing, the carbonization depth is more than two times higher than the carbonization depth of samples that were subjected to one-side freezing. Experiments have shown that with an increase of the number of cycles, the value of DF increases. At the same time, the damage of the samples during all-round freezing and thawing is, on average, $22 \%$ higher than the damage of the samples under the one-sided exposure of negative temperatures.

\section{Figure 2}

Effects of freezing conditions on the change in bending strength for samples from mortar

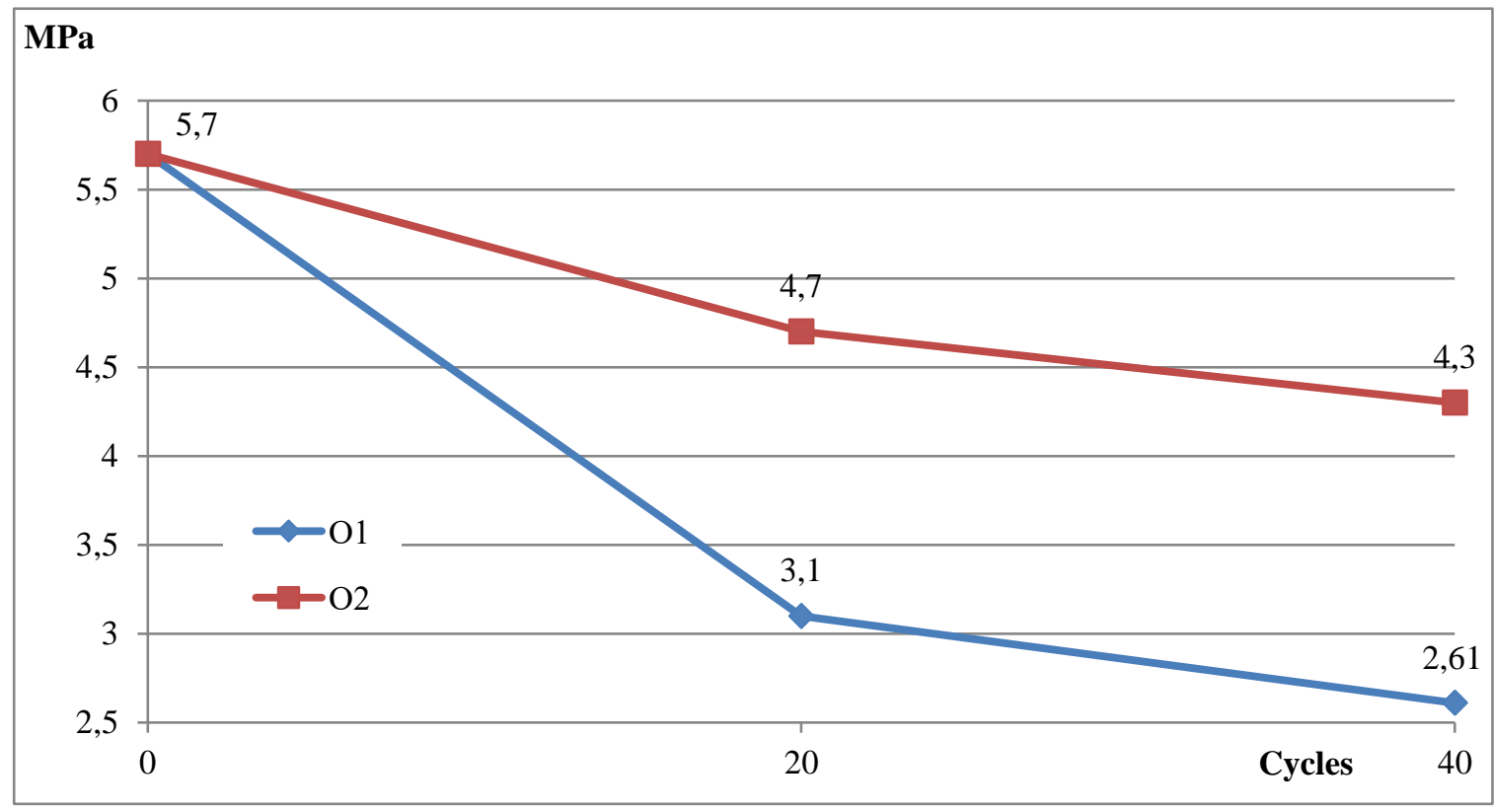

Source: Author's illustration 
Figure 3

Influence of freezing conditions on the change in compressive strength for samples from mortar

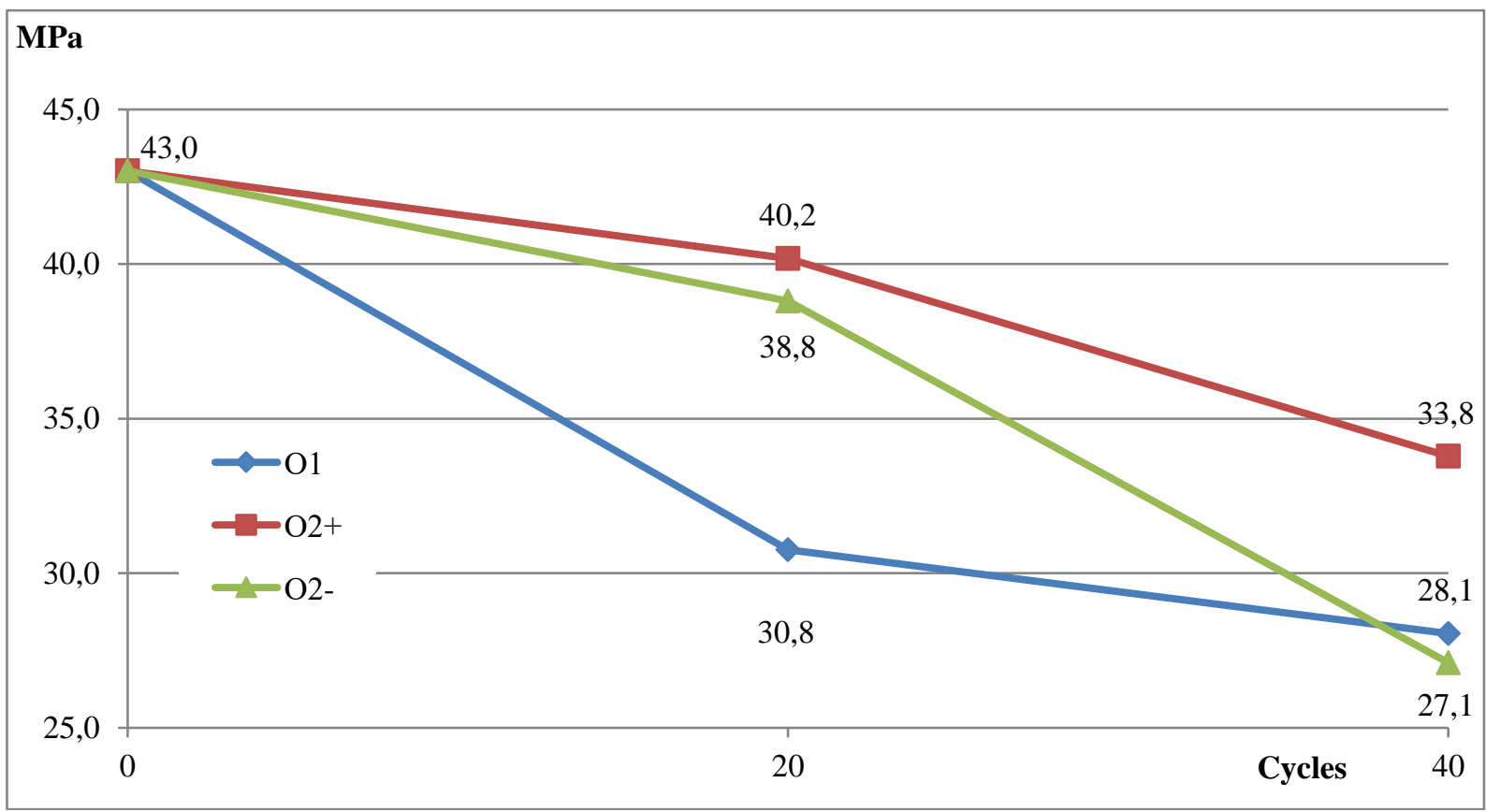

Source: Author's illustration

Experiments have shown that the strength of $\mathrm{f}_{\mathrm{ctk}}$, samples of cement-sand mortar after 40 cycles of comprehensive freezing decreased by $54 \%$, and with unilateral exposure to $24 \%$ (Figure 2).

Compressive strength $f_{c k}$ during freezing in all directions decreased by $34 \%$, while in unilateral freezing by $21 \%$. In the part that was subjected by cyclical stress, the $f_{c k}$ value decreased to $36 \%$.(Figure 3).

With an increasing of the number of cycles, the general tendention of the influence of freezing conditions on the change of strength characteristics remains.

Results similar to the mortar were obtained when studying the effect of freezing conditions on the change in the physical and mechanical properties of concrete.

The results of the experiment after 20 cycles of freezing and thawing showed that the water absorption for concrete samples that passed freezing fully increased by $34 \%$, while with one-sided freezing water absorption increased by $20 \%$. 
Figure 4

Influence of freezing conditions on the change in bending strength of concrete samples.

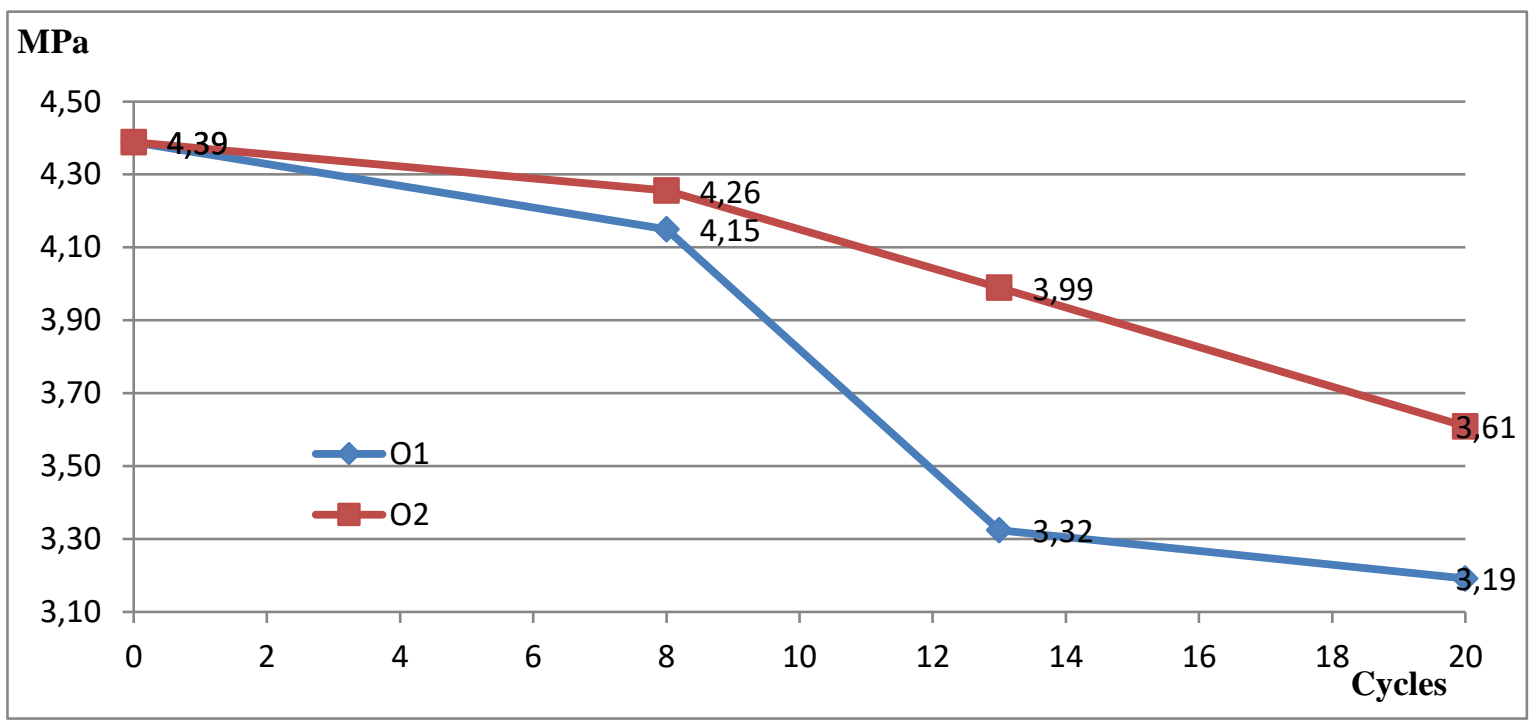

Source: Author's illustration

Figure 5

Influence of freezing conditions on the change in the splitting strength of concrete samples.

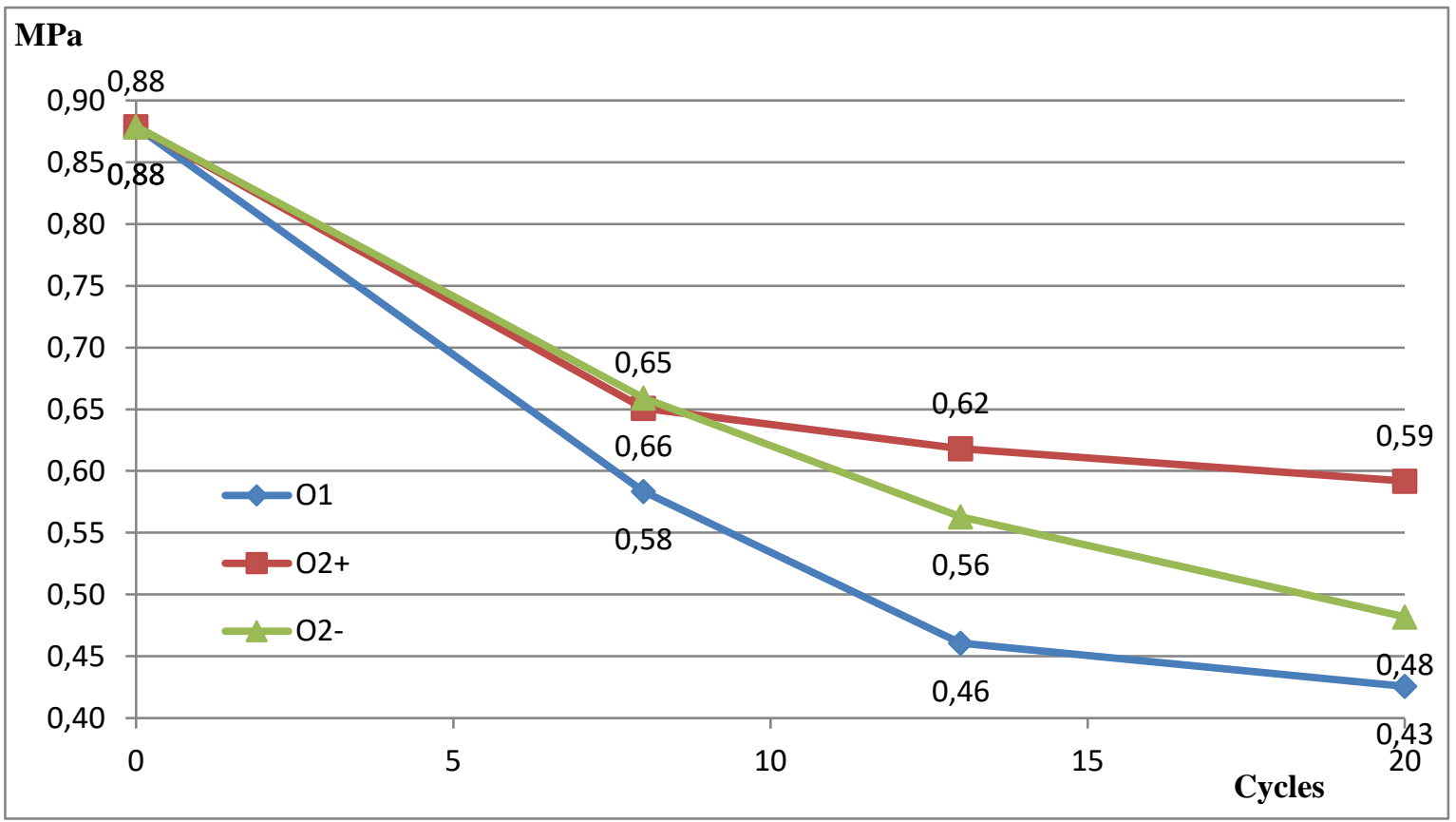

Source: Author's illustration 
Figure 6

Influence of freezing conditions on the change in the compressive strength of concrete samples.

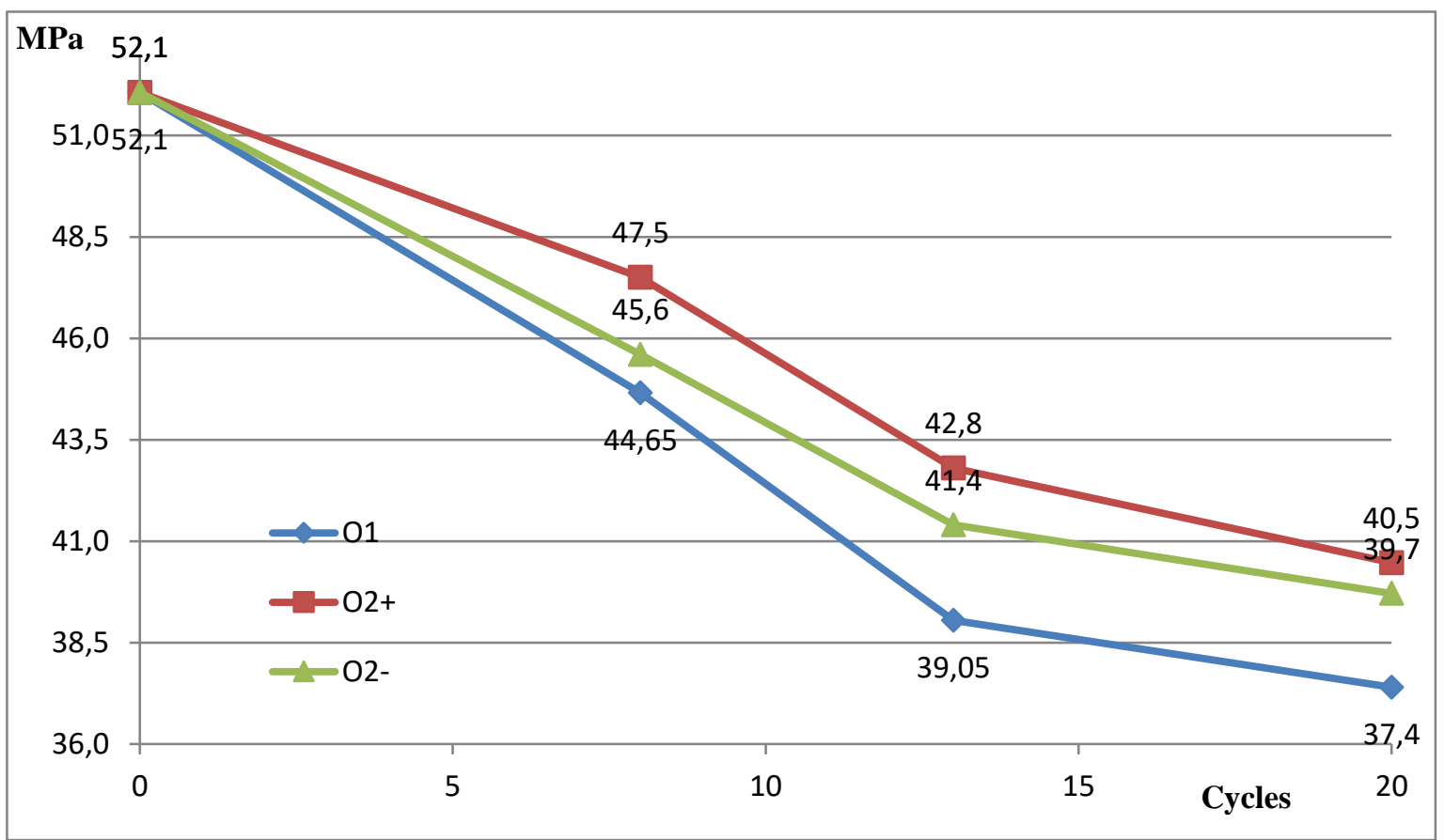

Source: Author's illustration

As already mentioned, the measurement of water absorption indicates a change in the pore structure, for concrete samples, which is indirectly confirmed by an increase in the ultrasound speed with an increase in the number of cycles. Also, the change in the structure is indirectly confirmed by the change in the damage coefficient (2) (Patent of Ukraine No. 5735). The damage coefficient of samples during all-round freezing and thawing is, on average, two times higher than the damage of samples under one-sided exposure of negative temperatures.

Another confirmation of structural transformations, for concrete samples, is the results of the freezing conditions effect on the change in the depth of carbonization: with all-round freezing. The depth of carbonization is more than two and half times higher than the depth of carbonization of samples that were subjected of unilateral freezing.

The experiments, for concrete samples, showed that the bending strength $\left(f_{c t k}\right)$ of concrete samples after 20 cycles of fully freezing decreased by $27 \%$, and samples that underwent local freezing by $18 \%$. (Figure 4$)$ The splitting strength $\left(f_{c t n}\right)$ in samples 01 decreased by $51 \%$, in $\mathrm{O} 2$ + by $35 \%$, and for $\mathrm{O} 2$ by $46 \%$ after 20 freeze-thaw cycles (Figure 5 ) The compressive strength of samples $\left(f_{c k}\right)$ after 20 freezing cycles decreased by $28 \%$ in samples O1, and for samples $\mathrm{O} 2$ + and $\mathrm{O} 2$ - this indicator decreased by $22 \%$ and $20 \%$, respectively (Figure 6). 


\section{Discussion}

Historically, the mechanism of displacing water from pores and capillaries was adopted by T. S. Powers (Powers, 1945) as the main one in describing of processes occurring in a separate capillary. This is the basis for the hypothesis of a decrease of frost resistance of building materials, and formulation and technological measures are being developed to create the so-called reserve porosity for the flow of water displaced during its freezing in the volume of capillaries. If we take a similar mechanism of internal heat and mass transfer as a basis, then under conditions of comprehensive freezing in the deep zones of samples (products) a significant amount of water will be concentrated, forming a "core" of material, supersaturated with moisture. With complete freezing, the pressure that arises with an increase of the volume of water should lead to the destruction of the sample (product) from the inside. Over the entire period of observation of the behavior of building products and structures and in the study of frost resistance on individual samples, the explosive nature of destruction by the "inside-out" method was not described. As a rule, the destruction of samples during all-round periodic freezing and thawing occurs from the surface layers to the deep layers of the material.

Experimental studies have shown that the frost resistance of the material largely depends on the freezing conditions of the samples. Freezing conditions predetermine structural changes, which affects the nature of damage changes, carbonization depth, water absorption, ultrasound transmission rate. In turn, a change of physical characteristics, as the studies have shown, leads to a change in mechanical indicators.

An analysis of the experimental data allows us to conclude that the decrease of frost resistance is associated not so much with the internal migration of moisture, but with the conditions of its increase in volume in the capillary and pore. Excessive pressure arises inside the discontinuities, which leads to an increasing in their volume. Thus, water is not displaced, but diffused in the discontinuity. This is especially noticeable because of changing the methods of freezing samples.

Sign-alternating volumetric deformations of the material arising due to periodic changes in the temperature and pressure of ice lead to a change in the structure, which in turn changes the physical and mechanical properties of cement stone and concrete, which are located in zones of negative temperatures.

\section{Conclusion}

The analysis of the experimental results showed that with an increase in the number of cycles in the samples from mortar and concrete, structural changes occur, which depend on the conditions of their freezing. This is evidenced by the change in mass, water absorption, ultrasound transmission rate, damage coefficients and carbonization depth, strength characteristics as follows: 
During cyclic all-round freezing, the water absorption of solution samples decreased by $25 \%$, the damage coefficient increased 9 times, and the ultrasound speed decreased to $7 \%$. Flexural strength decreased by $54 \%$, compressive strength by $34 \%$.

During local repeated freezing of samples from the solution, water absorption decreased by $18 \%$, the damage coefficient increased 6.5 times, and the ultrasound speed decreased to $8.8 \%$. Flexural strength decreased by $24 \%$ and compressive strength by $36 \%$.

During the volumetric freezing of concrete samples, water absorption increased by $34 \%$, the damage coefficient increased by 3.5 times, the ultrasound speed decreased to $47 \%$. Flexural strength decreased by $27 \%$, compressive strength decreased by $28 \%$.

Changing the freezing conditions leads to decreasing in water absorption up to $20 \%$, the damage coefficient -2 times, the ultrasound speed - up to 33\%. Flexural strength decreased by $18 \%$ and compression by $22 \%$.

Studies have shown that the change in the physical and mechanical characteristics and frost resistance of building materials depends on the conditions of exposure to negative temperatures.

\section{References}

Dobshits L. M. (2007). Obtaining concrete of increased durability for transport, industrial and civil structures. RIF "Rose of the World", pp. $25-28$.

DSTU B V.2.7-47-96. - ДСТУ Б В.2.7-47-96. (ГОСТ 10060.0-95). "Concrete. Methods for determining frost resistance. General requirements".

DSTU B V.2.7-47-96:2008 - ДСТУ Б B.2.7-47-96. "Building materials. Concrete. Methods for determining the average density, humidity, water absorption, porosity and water resistance"2008 "Building materials. Concrete. Methods for determining the average density, humidity, water absorption, porosity and water resistance"

DSTU B V.2.7-220:2009 - ДСТУ Б В.2.7-220: 2009 "Building materials. Concrete. Determination of strength by mechanical methods of non-destructive testing.

DSTU B V.2.7-214:2009 - ДСТУ Б В.2.7-214:2009 "Concretes. Methods for determining the strength of control samples".

Dvorkin L. I., Dvorkin O. L. (2003). On the similarity of concrete frost resistance structures. News of higher educational institutions. - Construction, vol. 1, pp. 34-37.

Khomenko A. A., Rogozha P. S., Ostra T. V. (2014). Развитие градиентов влажностных деформаций в неравномерно увлажненных конструкциях (Development of gradients of moisture deformations in unevenly moistened structures). Bulletin of ODABA, vol. 55, pp. 286-293.

Kuntsevich O.V. (1981). Concrete with high frost resistance for the extreme north (1st ed.). Stroyizdat.

Nepomyashchy O. M., Vyrovoy V. M., Makarova S. S., Khomenko A. A., (2020). Frost resistance of construction composites during one-sided freezing. Bulletin of ODABA, vol.79, pp. 109-116. 
Patent of Ukraine No. 5735: https://uapatents.com/2-5735-sposib-viyavlennyatrishhin-betonnikh-ta-zalizobetonnikh-konstrukcijj-na-neorganichnomuvyazhuchomu.html

Podvalny A. M. (2004). About the concept of providing frost resistance of concrete in the structures of buildings and structures. Stroitelnye materialy, vol. 6, pp. 4-6.

Powers T. C. (1945) Basic considerations pertaining to freezing and thawing tests (1st ed.). Proc. Am. Concrete Inst.

Rusin Z. (2002). Technologia betonow mrozodpornych (1st ed.). Polski cement Sp. Zoo.

Sheikin A.E., Dobshits L. M. (1989). Cement concrete with high frost resistance (1st ed.). Stroyizdat.

Sumgin M. I. (1927). Permafrost of the soil within the USSR (1st ed.). Publishing house of the Academy of Sciences of the USSR.

Vyrovoy V. N., Dorofeev V. S., Sukhanov V. G. (2010). Composite building materials and structures, structure, self-organization properties (1st ed.). Odessa "TES".

Vyrovoy V. N., Zakorchemnaya N. O., Zakorchemny Yu. O. (2007). Анализ механизма развития трещин при замерзании в их объеме воды (Analysis of the mechanism of crack development during freezing in their volume of water). DonNACEA Bulletin, vol. 1(63), pp. 96-100.

\section{About the authors}

Nepomyach Alexander Nikolaevich - assistant at the Department of Production of Building Products and Structures of Odessa State Academy of Civil Engineering and Architecture. This work is a part of the dissertation work "Mechanism of resistance to frost destruction of building structures." The main part of the work is devoted to the analysis of real external influences on the structure and the mechanism of their flow. (lottor27@gmail.com)

Vyrovoy Valeriy Nikolaevich - Doctor of Technical Sciences, Professor of the Department of Production of Building Products and Structures of Odessa State Academy of Civil Engineering and Architecture. Research interests - structure formation and destruction of composite materials as open self-organizing systems. (vyrovoy@ukr.net)

Chistyakov Artem Aleksaedrovich - postgraduate student of Department of Construction Technology of Odessa State Academy of Civil Engineering and Architecture. (artemchis@gmail.com) 